\title{
Produção e qualidade comercial de alface fertirrigada com nitrogênio e potássio em ambiente protegido
}

\author{
Roberto Rezende ${ }^{1}$, Renan Soares de Souza ${ }^{2}$, André Maller ${ }^{1 *}$ Paulo Sérgio Lourenço de Freitas ${ }^{1}$, \\ Antônio Carlos Andrade Gonçalves ${ }^{1}$, Graziela Silva Rezende ${ }^{3}$
}

10.1590/0034-737X201764020014

\section{RESUMO}

A adubação orgânica pode fornecer grande parte dos nutrientes necessários à cultura da alface. No entanto, a taxa de mineralização de nutrientes pode ser limitante à absorção, sendo que outras formas de adubação complementares com fertilizantes solúveis podem ser utilizadas, como a fertirrigação. O objetivo deste trabalho foi avaliar o efeito da fertirrigação por gotejamento, com nitrogênio e potássio, aliada à adubação de plantio, no crescimento da alface Vera, cultivada em ambiente protegido. O experimento foi realizado entre agosto e outubro de 2012 (inverno e primavera; 67 dias). O delineamento experimental foi inteiramente aleatorizado, com três repetições. Os tratamentos foram formados pela matriz Plan Puebla III, isto é, da combinação entre cinco doses de nitrogênio (N) $\left(9 ; 54 ; 90 ; 126\right.$ e $\left.171 \mathrm{~kg} \mathrm{ha}^{-1}\right)$ e cinco doses de potássio $\left(1,15 ; 6,90 ; 11,50 ; 16,10\right.$ e 21,85 $\left.\mathrm{kg} \mathrm{ha}^{-1}\right)$, além da testemunha, que não recebeu fertirrigação. Concluiuse que a fertirrigação pode ser utilizada para o crescimento da cultura mesmo com adubação orgânica de plantio. As maiores doses de $\mathrm{N}$ e de $\mathrm{K}_{2} \mathrm{O}$ resultaram no maior número de folhas comerciais por planta. Os aumentos das doses de $\mathrm{N}$ e de $\mathrm{K}_{2} \mathrm{O}$ promoveram incrementos da matéria fresca não comercial da parte aérea, sem prejuízo à qualidade comercial.

Palavras-chave: Lactuca sativa L.; microirrigação; casa de vegetação; matéria fresca comercial.

\section{ABSTRACT}

\section{Production and commercial quality of lettuce fertirrigated with nitrogen and potassium in greenhouse}

Organic fertilization can provide most of the nutrients needed to grow lettuce crop. However, the rate of nutrient mineralization may be limiting to absorption, once complementary forms of fertilization with soluble fertilizers can be used, such as fertirrigation. The objective of this work was to evaluate the effect of the drip fertirrigation with nitrogen and potassium with organic fertilization in the production and commercial quality of the Vera lettuce cultivated in greenhouse. The cultivation period used for the experiment was between August and October 2012 (winter and spring; 67 days). The experimental design was completely randomized with three replications, in which ten treatments were evaluated, with nine of them formed by the Plan Puebla III matrix, that is, from the combination among five N (9, 54, 90, 126 , and $\left.171 \mathrm{~kg} \mathrm{ha}^{-1}\right)$ and five $\mathrm{K}$ doses $\left(1.15,6.90,11.50,16.10\right.$, and $\left.21.85 \mathrm{~kg} \mathrm{ha}^{-1}\right)$, applied in topdressing, and one of them as control, which did not receive fertirrigation. The best answer to the shoot commercial fresh mass took place with the maximum dose of $\mathrm{Si}$ and $\mathrm{K}_{2} \mathrm{O}$ and in the zero dose of $\mathrm{N}$. The commercial leaf number per plant showed their higher values in the maximum doses of $\mathrm{N}$ and $\mathrm{Si}$ and $\mathrm{K}_{2} \mathrm{O}$. The shoot noncommercial fresh mass increment, both with the increase in $\mathrm{N}$ doses and with the increase in $\mathrm{Si}$ and $\mathrm{K}_{2} \mathrm{O}$ doses, did not harm the commercial quality.

Key words: Lactuca sativa L.; micro-irrigation; greenhouse; commercial fresh mass.

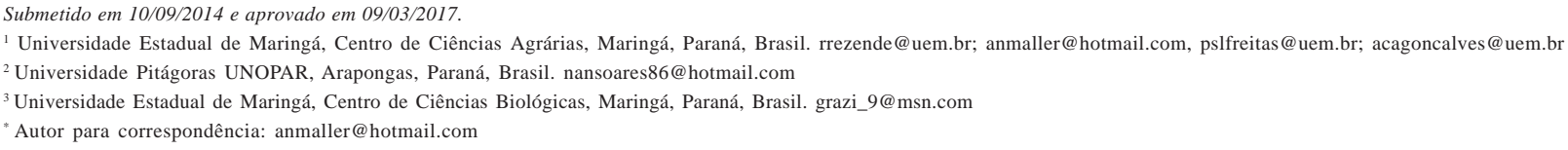




\section{INTRODUÇÃO}

A alface (Lactuca sativa L.) é uma olerícola folhosa que pertence à família Asteraceae, e que pode ser cultivada tanto no campo quanto em ambiente protegido, ocorrendo em praticamente todas as regiões do Brasil (Carvalho Filho et al., 2009).

A necessidade de fornecimento de produtos in natura e de boa qualidade, durante todo o ano, contribuiu para a difusão do sistema de produção baseado na proteção de culturas, com crescimento da utilização de ambientes protegidos para produção de hortaliças e flores (Maggi et al., 2006). Em cultivo protegido, a única forma de repor a água consumida pela cultura e evaporada pelo ambiente é pela irrigação, que, manejada adequadamente, supre suas necessidades hídricas (Santos \& Pereira, 2004). Em ambiente protegido, o sistema de irrigação mais recomendado e utilizado é o de gotejamento (Carrijo et al., 1999).

A fertirrigação corresponde à dissolução de certos fertilizantes na água de irrigação e a aplicação é efetuada por um sistema de irrigação, sendo o mais utilizado o de gotejamento, constituindo uma maneira mais eficiente de aumentar a disponibilidade e a absorção de nutrientes (Fernandes \& Martins, 1999). De acordo com Duenhas et al. (2002), quanto à fertirrigação, ainda há necessidade de pesquisas sobre doses, concentração e parcelamento de adubos para as culturas.

Os nutrientes que a alface mais acumula na sua parte aérea são o potássio e o nitrogênio, em cultivo no solo (Beninni et al., 2005), o que fornece uma ideia do alto requerimento desses nutrientes pela cultura. Do ponto de vista do aspecto produtivo da alface, relatos dos benefícios da adubação nitrogenada podem ser encontrados nos trabalhos realizados por Yuri (2004), Mantovani et al. (2005), Silva et al. (2008) e Resende et al. (2012) e, sobre os da adubação potássica, em Yuri (2004) e Koetz et al. (2006).

A resposta da alface, cultivar Raider, conduzida sob quatro doses de adubação em cobertura de nitrogênio ( 0 , 60,120 e $180 \mathrm{~kg} \mathrm{ha}^{-1}$ ), adicionais à dose de $60 \mathrm{~kg} \mathrm{~N} \mathrm{ha}^{-1}$, aplicada no plantio, e de cinco doses de molibdênio por via foliar $\left(0,0 ; 35,1 ; 70,2 ; 105,3\right.$ e 140,4 $\left.\mathrm{g} \mathrm{ha}^{-1}\right)$, foi avaliada por Resende et al. (2012). Esses autores constataram que, na ausência de molibdênio, a maior quantidade de matéria fresca comercial ocorreu com a dose de $66,4 \mathrm{~kg} \mathrm{~N} \mathrm{ha}^{-1}$, e que, com a dose de 140,4 $\mathrm{g} \mathrm{ha}^{-1}$ de molibdênio, obteve-se a melhor resposta dessa característica com a dose de 102,8 $\mathrm{kg} \mathrm{N} \mathrm{ha}^{-1}$.

A produtividade da alface, cultivar Raider, foi avaliada por Koetz et al. (2006), ao estudarem diferentes turnos de rega, associados a quatro doses de cloreto de potássio $\left(100,150,200\right.$ e $\left.250 \mathrm{~kg} \mathrm{ha}^{-1}\right)$, aplicadas por fertirrigação, em casa de vegetação. Esses autores constataram que a pro- dutividade foi influenciada pelas doses de potássio e que a melhor produtividade ocorreu com a dose ótima de 119,36 $\mathrm{kg} \mathrm{ha}^{-1}$ de $\mathrm{K}_{2} \mathrm{O}$ ou 198,93 $\mathrm{kg} \mathrm{ha}^{-1}$ de $\mathrm{KCl}$.

Considerando-se o exposto, este trabalho objetivou avaliar o efeito da aplicação de doses de nitrogênio $(\mathrm{N})$ em cobertura e de potássio $\left(\mathrm{K}_{2} \mathrm{O}\right)$, por fertirrigação, em sistema de irrigação por gotejamento, sobre a produção e qualidade comercial de alface crespa, cultivar Vera, em ambiente protegido.

\section{MATERIAL E MÉTODOS}

O experimento foi realizado em casa de vegetação do tipo teto em arco, localizada no Centro Técnico de Irrigação (CTI), da Universidade Estadual de Maringá (UEM), em Maringá, PR, situada nas coordenadas 2323'56,50" S e $51^{\circ} 57^{\prime} 7,53^{\prime \prime} \mathrm{O}$, em altitude de $512 \mathrm{~m}$. A casa de vegetação é coberta com filme de polietileno de $150 \mu \mathrm{m}$ de espessura, no teto, e envolta com tela de sombrite nas laterais. $\mathrm{O}$ experimento correspondeu ao período de cultivo entre agosto e outubro de 2012 (inverno e primavera; 67 dias).

O clima local é caracterizado por ser da classe $\mathrm{Cfa}$, ou seja, subtropical, conforme Köppen (1948). O solo da área experimental foi classificado como Nitossolo Vermelho distroférrico (Embrapa, 2013) e sua caracterização química, na profundidade de $0,10 \mathrm{~m}$, é: $\mathrm{pH}\left(\mathrm{CaCl}_{2}\right)-7,10 ; \mathrm{pH}\left(\mathrm{H}_{2} \mathrm{O}\right)$ 7,90; matéria orgânica e C-25,57 e 14,83 $\mathrm{g} \mathrm{dm}^{-3}$, respectivamente; $\mathrm{P}=214,59 \mathrm{mg} \mathrm{dm}{ }^{-3} ; \mathrm{K}^{+}, \mathrm{Ca}^{+2}, \mathrm{Mg}^{+2}, \mathrm{Al}^{+3}, \mathrm{H}^{+}+\mathrm{Al}^{+3}$, soma de bases e capacidade de troca catiônica $=0,46 ; 6,68$; 1,$53 ; 0,00 ; 1,75 ; 8,67$ e 10,42 $\mathrm{cmol}_{\mathrm{c}} \mathrm{dm}^{-3}$, respectivamente; saturação por bases=83,21\%; e $\mathrm{S}=10,62 \mathrm{mg} \mathrm{dm}^{-3}$.

Inicialmente, procedeu-se ao revolvimento do solo da área experimental com enxada rotativa, que possibilitou material de solo suficiente para a construção de três canteiros de $14 \mathrm{~m}$ de comprimento, 1,2 $\mathrm{m}$ de largura e 0,1 $\mathrm{m}$ de altura. Cada canteiro foi dividido longitudinalmente ao meio e, transversalmente, em cinco partes iguais, de modo a totalizar 30 frações de área, que corresponderam à localização das parcelas experimentais. O solo recebeu adubação de base com $5000 \mathrm{~kg}$ de esterco de galinha e 40 $\mathrm{kg}$ de $\mathrm{N} \mathrm{ha}^{-1}$. Para esta última, a fonte de $\mathrm{N}$ utilizada foi a $\operatorname{ureia}(45 \% \mathrm{~N})$.

O sistema de irrigação foi o por gotejamento, mediante acionamento de uma bomba centrífuga de $0,5 \mathrm{CV}$ de potência, conectada a um reservatório (caixa d' água) com 500 L de capacidade. Da bomba, derivou-se uma linha principal, de PVC, com 32 mm de diâmetro, e, desta, partiram cinco linhas de derivação perpendiculares, também de PVC com 32 mm de diâmetro, as quais foram alocadas nas divisões transversais dos canteiros. As outras extremidades das linhas de derivação conectaram-se a outra linha principal, de PVC, com 32 mm de diâmetro, relacio- 
nada com o retorno até à caixa d'água ou até o ponto de partida inicial.

Seis registros foram instalados em cada linha de derivação, cada qual correspondente às divisões longitudinais dos canteiros e, desta forma, ao controle da irrigação e fertirrigação de uma parcela experimental. Portanto, no total, utilizaram-se 30 desses registros, sendo que, de cada um e em cada parcela, houve saídas duplas para duas linhas laterais, constituídas de tubos gotejadores de polietileno, com diâmetro de $16 \mathrm{~mm}$, instaladas no sentido do comprimento do canteiro e que continham, individualmente, 12 gotejadores autocompensantes. O valor médio de vazão por emissor foi de $0,85 \mathrm{~L} \mathrm{~h}^{-1}$, a uma pressão de operação de 10 m.c.a, utilizada, posteriormente, nos procedimentos de irrigação e fertirrigação.

A semeadura foi realizada em bandejas de isopor de 128 células. Primeiramente, foram elas preenchidas com substrato comercial e, posteriormente, uma semente peletizada de alface crespa, cultivar Vera, foi adicionada em cada célula. O transplantio para o solo ocorreu 26 dias após a semeadura, no espaçamento de 0,20 m x 0,20 m, quando as mudas apresentavam quatro folhas. Para cada parcela experimental, foram transplantadas 36 mudas de alface, distribuídas em três fileiras de 12 plantas, de modo que uma delas permanecesse no limite divisório central entre as duas linhas laterais de irrigação e fertirrigação.

A decisão quanto ao momento de se irrigar ocorreu por meio da leitura de três tensiômetros, instalados em diagonal na área experimental, a 0,10 m de profundidade, e, para tanto, com base em dados de Santos \& Pereira (2004) e de Vilas Boas et al. (2007), estabeleceu-se como referência para o momento de irrigação a tensão de água no solo de $15 \mathrm{kPa}$.

Foram avaliados dez tratamentos, sendo que nove deles resultaram da combinação entre doses de nitrogênio em cobertura (N) $\left(9 ; 54 ; 90 ; 126\right.$ e $\left.171 \mathrm{~kg} \mathrm{ha}^{-1}\right)$ e doses de potássio em cobertura $\left(\mathrm{K}_{2} \mathrm{O}\right)(1,15 ; 6,90 ; 11,50 ; 16,10$ e 21,85 $\mathrm{kg} \mathrm{ha}^{-1}$ ), definida conforme a matriz Plan Puebla III (Turrent \& Laird, 1975). Um deles constituiu na testemunha que não recebeu adubação de cobertura com doses de $\mathrm{N}$ e de $\mathrm{K}_{2} \mathrm{O}$. Os tratamentos foram dispostos em um delineamento inteiramente aleatorizado, com três repetições e, assim, houve a formação de 30 parcelas experimentais.

As aplicações das doses de $\mathrm{N}$ e de $\mathrm{K}_{2} \mathrm{O}$ ocorreram mediante uso do sistema de irrigação por gotejamento, descrito anteriormente, utilizando-se como fontes de nutrientes a ureia $(45 \% \mathrm{~N})$ e produto líquido comercial, este último à base de silicato de potássio e com garantias de $12 \%$ de Si solúvel em água (165,6 $\left.\mathrm{g} \mathrm{L}^{-1}\right)$ e de $12 \%$ de $\mathrm{K}_{2} \mathrm{O}$ solúvel em água $\left(165,6 \mathrm{~g} \mathrm{~L}^{-1}\right)$.

A parcela experimental tinha as dimensões de 2,4 $\mathrm{m}$ de comprimento, 0,6 m de largura e 0,10 m de altura, com área útil de $0,32 \mathrm{~m}^{2}$, composta pelas oito plantas centrais da parcela, localizadas na sua fileira de plantio central.
A fertirrigação foi realizada separadamente, para nitrogênio (ureia) e potássio, e foram totalizadas quatro aplicações, correspondentes à divisão das doses totais $\left(\mathrm{kg} \mathrm{ha}^{-1}\right)$ em quatro, as quais foram realizadas com periodicidade semanal. De maneira a facilitar o procedimento de fertirrigação nitrogenada, isto é, pré-dissolver o fertilizante, inicialmente, preparou-se uma solução de ureia na concentração de $10 \%$ de $\mathrm{N}\left(\mathrm{m} \mathrm{v}^{-1}\right)$. A aplicação dos tratamentos foi realizada com um volume de calda por tratamento de 15 litros. As doses parciais de $\mathrm{K}_{2} \mathrm{O}$, isto é, por aplicação ou fertirrigação ( $1 / 4$ da dose total) foram de 0,$05 ; 0,30$; 0,50; 0,70 e 0,95 mL por L de água, que são, respectivamente, correspondentes às doses totais de $\mathrm{K}_{2} \mathrm{O}$ de 1,15; 6,90; 11,$50 ; 16,10$ e $21,85 \mathrm{~kg} \mathrm{ha}^{-1}$.

Por ocasião da colheita, as seguintes características foram avaliadas: matéria fresca total da parte aérea (MFTPA; g por planta), matéria fresca comercial da parte aérea (MFCPA; g por planta), matéria fresca não comercial (não aproveitável) da parte aérea (MFNCPA; g por planta), número de folhas comerciais (NFC) e índice comercial (IC).

Inicialmente, a planta foi pesada em balança digital para determinação da MFTPA. O mesmo procedimento ocorreu para obtenção da MFCPA, porém, antes da pesagem, as folhas senescentes e ou danificadas (região externa da planta), isto é, as folhas que não tinham condições de serem aproveitadas para o comércio, foram retiradas. Posteriormente, para a contagem e determinação do NFC, o desfolhamento da planta foi necessário, considerando-se comercial a folha passível de comercialização e consumo. Pela diferença entre a MFTPA e a MFCPA, obteve-se a MFNCPA, a qual corresponde à massa das folhas senescentes e ou danificadas (região externa da planta). A determinação do IC ocorreu pela razão entre a MFCPA e a MFTPA, com base em trabalhos de Santos et al. (2011).

As características foram estudadas mediante análise de regressão linear múltipla, cujo procedimento de seleção de modelos estatísticos baseou-se nos seguintes critérios: teste $F$ significativo para a regressão $(p<0,05)$; teste $F$ não significativo para a falta de ajustamento $(\mathrm{p} \geq 0,05)$; teste $t$ de Student significativo para coeficientes de regressão ( $\mathrm{p}<0,05)$ e coeficiente de determinação ajustado $\left(\mathrm{R}_{\text {aj }}^{2}\right)$. O programa utilizado na realização das análises estatísticas foi o SISVAR. O modelo estatístico completo é o apresentado a seguir:

$\mathrm{v}=\hat{\mathrm{a}}_{0}+\hat{\mathrm{a}}_{1}(\mathrm{~N})+\hat{\mathrm{a}}_{2}\left(\mathrm{~K}_{2} \mathrm{O}\right)+\hat{\mathrm{a}}_{3}(\mathrm{~N})^{2}+\hat{\mathrm{a}}_{4}\left(\mathrm{~K}_{2} \mathrm{O}\right)^{2}+\hat{\mathrm{a}}_{5}(\mathrm{~N})\left(\mathrm{K}_{2} \mathrm{O}\right)$,

em que v-valor estimado da característica em questão; $\hat{a}_{0}$, $\hat{\mathrm{a}}_{1}, \hat{\mathrm{a}}_{2}, \hat{\mathrm{a}}_{3}, \hat{\mathrm{a}}_{4}, \hat{\mathrm{a}}_{5}$, coeficientes de regressão; N-dose de N $\left(\mathrm{kg} \mathrm{ha}^{-1}\right)$; e $\mathrm{K}_{2} \mathrm{O}$-dose de $\mathrm{K}_{2} \mathrm{O}\left(\mathrm{kg} \mathrm{ha}^{-1}\right)$. A partir e além deste foram estudados outros 11 modelos lineares possíveis anteriores. 


\section{RESULTADOS E DISCUSSÃO}

$\mathrm{Na}$ análise de regressão, os resultados foram semelhantes entre matéria fresca total da parte aérea e matéria fresca comercial da parte aérea, para as quais foi possível observar que a fertirrigação com nitrogênio e a fertirrigação com potássio, assim como a interação entre as doses de $\mathrm{N}$ e $\mathrm{K}_{2} \mathrm{O}$, influenciaram significativamente essas variáveis resposta (Figuras 1A e 1B).

A fertirrigação com potássio causou a maior variação de matéria fresca total da parte aérea, entre a dose zero de $\mathrm{K}_{2} \mathrm{O}$ e a maior dose $\left(21,85 \mathrm{~kg} \mathrm{ha}^{-1}\right)$, e também foi responsável pela melhor resposta da característica $(298,24 \mathrm{~g}$ por planta), com a dose máxima de $\mathrm{K}_{2} \mathrm{O}$ e com ausência de fertirrigação com nitrogênio (Figura 1A).

Para matéria fresca comercial da parte aérea, a maior variação também foi causada pela fertirrigação com potássio, entre as doses de 0 a 21,85 $\mathrm{kg} \mathrm{ha}^{-1}$ de $\mathrm{K}_{2} \mathrm{O}$, e a melhor resposta da característica (291,67 g por planta) foi observada com a dose máxima de $\mathrm{K}_{2} \mathrm{O}$ e com ausência de fertirrigação com nitrogênio (Figura 1B).

Houve influência significativa e negativa da interação entre as doses de $\mathrm{N}$ e $\mathrm{K}_{2} \mathrm{O}$ sobre as quantidades de matérias fresca e total da parte aérea. Para cada superfície de resposta, o ponto de inflexão foi determinado analiticamente por meio da derivada parcial dos modelos estatísticos selecionados para essas características. Esse ponto representa a dose de $\mathrm{K}_{2} \mathrm{O}$ a partir da qual o aumento das doses de $\mathrm{N}$ resulta em decréscimos da matéria fresca total e da matéria fresca comercial da parte aérea, assim como a dose de $\mathrm{N}$ a partir da qual o aumento das doses de $\mathrm{K}_{2} \mathrm{O}$ resulta nesse mesmo efeito.

Os pontos de inflexão, a partir dos quais ocorre interação negativa entre as doses de $\mathrm{Ne} \mathrm{K}_{2} \mathrm{O}$, corresponderam às doses de $17,88 \mathrm{~kg} \mathrm{ha}^{-1}$ de $\mathrm{K}_{2} \mathrm{O}$ e de $169,78 \mathrm{~kg}^{-}$ ${ }^{1}$ de $\mathrm{N}$, para matéria fresca total da parte aérea, e às doses de $17,00 \mathrm{~kg} \mathrm{ha}^{-1}$ de $\mathrm{K}_{2} \mathrm{O}$ e de $166,66 \mathrm{~kg} \mathrm{ha}^{-1}$ de $\mathrm{N}$ para matéria fresca comercial da parte aérea (Figuras 1A e 1B).

A matéria fresca não comercial da parte aérea foi influenciada significativamente pela fertirrigação nitrogenada e pela fertirrigação com potássio, sendo que houve resposta linear crescente dessa característica com o aumento da dose de $\mathrm{N}$ (Figura 2A) e com o aumento da dose de $\mathrm{K}_{2} \mathrm{O}$ (Figura 2B).

Cada $25 \mathrm{~kg} \mathrm{ha}^{-1}$ acrescidos à dose de nitrogênio foi responsável pelo incremento de $0,72 \mathrm{~g}$ por planta da matéria fresca não comercial da parte aérea (Figura 2A), enquanto o aumento de $2,5 \mathrm{~kg} \mathrm{ha}^{-1}$ de $\mathrm{K}_{2} \mathrm{O}$ proporcionou acréscimo de $0,48 \mathrm{~g}$ por planta dessa variável resposta (Figura 2B). Na fertirrigação com nitrogênio, a maior resposta (11,66 g por planta) de matéria fresca não comercial da parte aérea ocorreu com a dose máxima utilizada $(171 \mathrm{~kg}$ ha $^{-1}$ de N) (Figura 2A) e, no caso da fertirrigação com potássio, a máxima dose utilizada $\left(21,85 \mathrm{~kg} \mathrm{ha}^{-1} \mathrm{de}_{2} \mathrm{O}\right)$ também proporcionou o maior resultado para essa característica (11,31 g por planta) (Figura 2B).

Tanto a fertirrigação com nitrogênio quanto a com potássio influenciaram significativamente o número de folhas

B.

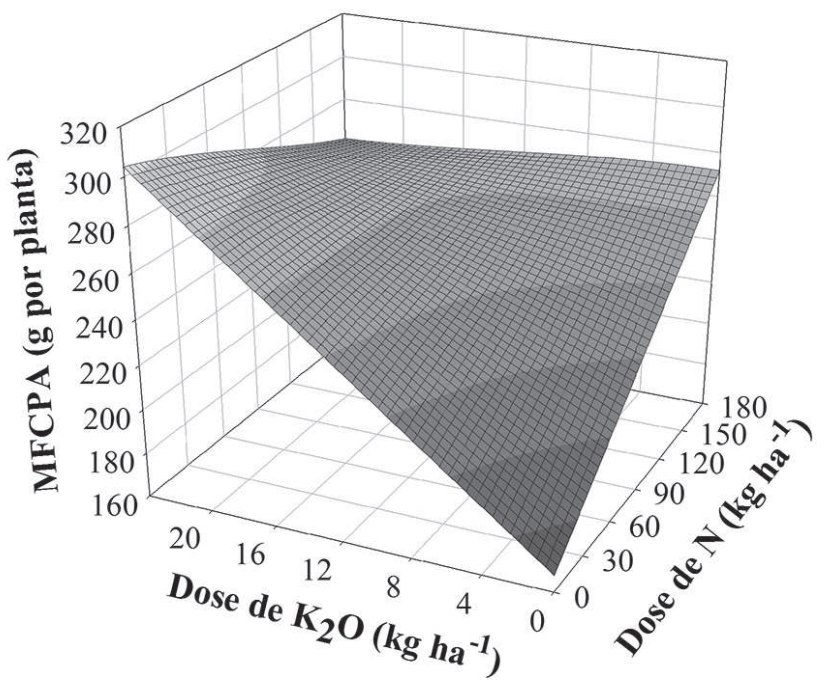

$$
\begin{gathered}
\text { MFTPA }=175,9530+5,8949 \cdot 10^{-1 *} \cdot(\mathrm{N})+5,5967 * .\left(\mathrm{K}_{2} \mathrm{O}\right) \\
-3,2964 \cdot 10^{-2 *} \cdot(\mathrm{N}) .\left(\mathrm{K}_{2} \mathrm{O}\right) \\
\mathrm{R}^{2}{ }_{\mathrm{aj}}{ }^{(\mathrm{a})}=0,7014
\end{gathered}
$$

Figura 1: Matéria fresca total da parte aérea (MFTPA) (A) e matéria fresca comercial da parte aérea (MFCPA) (B), em função de doses de $\mathrm{N}$ e de $\mathrm{K}_{2} \mathrm{O}$. " Significativo pelo teste $\mathrm{t}$ de Student ( $\left.<<0,05\right) ;{ }^{(a)}$ Coeficiente de determinação ajustado. 
comerciais por planta, sendo que o aumento da dose de $\mathrm{N}$ (Figura 3A) e o aumento da dose de $\mathrm{K}_{2} \mathrm{O}$ (Figura 3B) causaram resposta linear crescente dessa variável resposta.

De acordo com o que mostra a Figura $3 \mathrm{~A}$, a cada $25 \mathrm{~kg}$ ha $^{-1}$ acrescidos à dose de nitrogênio, o número de folhas comerciais foi incrementado em 0,38 folhas por planta, com a melhor resposta $(23,00$ folhas por planta) com a dose máxima de $\mathrm{N}\left(171 \mathrm{~kg} \mathrm{ha}^{-1}\right)$, enquanto, conforme o que mostra a Figura $3 \mathrm{~B}$, a adição de $2,5 \mathrm{~kg} \mathrm{ha}^{-1}$ à dose de $\mathrm{K}_{2} \mathrm{O}$ proporcionou aumento de 0,28 folhas por planta nessa variável resposta, cujo melhor resultado $(22,92$ folhas por planta) ocorreu com a maior dose de $\mathrm{K}_{2} \mathrm{O}\left(21,85 \mathrm{~kg} \mathrm{ha}^{-1}\right)$.

Nenhum modelo estatístico foi selecionado para índice comercial, isto é, as fertirrigações com nitrogênio e com potássio não influenciaram de maneira significativa esta característica, cuja média geral foi de 0,96 .

O favorecimento da matéria fresca não comercial da parte aérea, que ocorreu graças à fertirrigação com nitrogênio e com potássio (Figuras 2A e 2B), provavelmente, acompanhou o favorecimento da matéria fresca total da parte aérea, que ocorreu mediante a aplicação de nitrogênio e potássio por via da água de irrigação (Figura 1A). Entretanto, esse crescimento da matéria fresca não comercial da parte aérea não foi suficiente para afetar de maneira negativa a qualidade comercial de alface, uma vez que a matéria fresca comercial da parte aérea também foi beneficiada pelas fertirrigações com todos os nutrientes (Figura 1B).

O fato mencionado no parágrafo anterior pode ser corroborado pelos resultados obtidos para número de folhas comerciais por planta, o qual foi beneficiado com a fertirrigação com nitrogênio e pela fertirrigação com potássio (Figuras 3A e 3B) e que também não foi afetado negativamente, ainda que tenha ocorrido aumento da ma- téria fresca não comercial da parte aérea. Ainda corrobora esse fato o índice comercial, cuja resposta não evidenciou influência significativa das fertirrigações e cuja média de 0,96 indica resultado de qualidade comercial muito bom.

A maior variação, ocorrida nas quantidades de matérias frescas total e comercial da parte aérea, por meio da aplicação de potássio, e as melhores respostas obtidas pela fertirrigação com as máximas doses de $\mathrm{K}_{2} \mathrm{O}$ e na dose zero de nitrogênio, pode ser atribuída, provavelmente, a um maior efeito do potássio sobre essas variáveis resposta. Isto pode ser justificado graças ao fato de ser o potássio o elemento mais acumulado pela parte aérea de alface cultivada em sistema convencional (solo) (Beninni et al., 2005), o que ressalta seu grande requerimento por esta cultura. Estas últimas respostas ainda podem ter sido potencializadas pela grande quantidade de potássio já presente no solo da área experimental.

A adubação de plantio, composta por esterco de galinha e ureia, elevou os níveis de $\mathrm{N}$ e de $\mathrm{K}$ na área experimental, o que pode ter reduzido a contribuição da fertirrigação para o crescimento da cultura. No entanto, a fertirrigação promove a disponibilização de nutrientes para a solução no solo de forma imediata (Frizzone et al., 2012), enquanto a taxa de mineralização de $\mathrm{N}$ e de $\mathrm{K}$ da matéria orgânica pode não ter sido suficiente para suprir a necessidade diária da cultura. As Figuras 1, 2 e 3 mostram que, mesmo com a adubação orgânica, as plantas tiveram menor crescimento sem aplicação de nutrientes na forma líquida. A taxa de absorção de nitrogênio da alface é baixa no início do ciclo e tende a aumentar com a taxa de crescimento da planta (Martins et al., 2009).

A fertirrigação nitrogenada, aliada à adubação orgânica, pode levar a decréscimo do crescimento da alface, caso o nitrogênio total disponibilizado esteja além das necessi-
A.

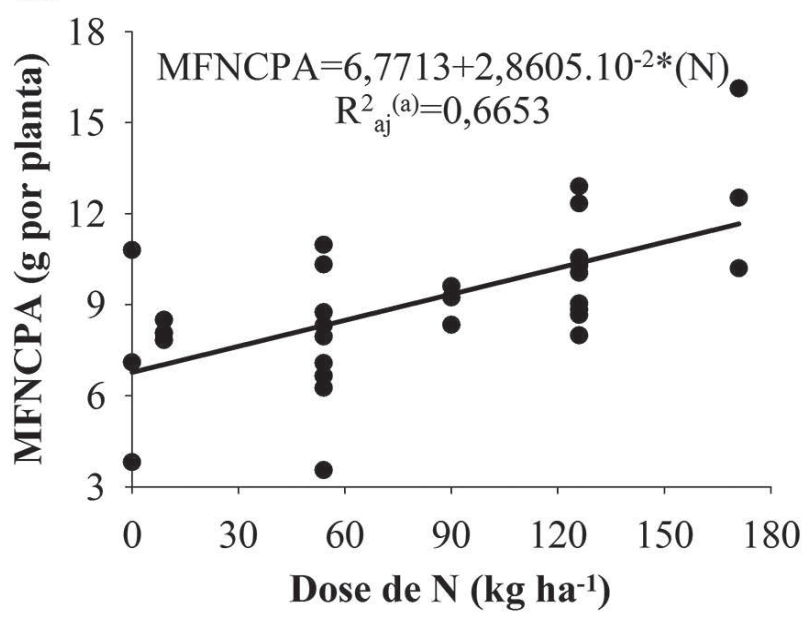

B.

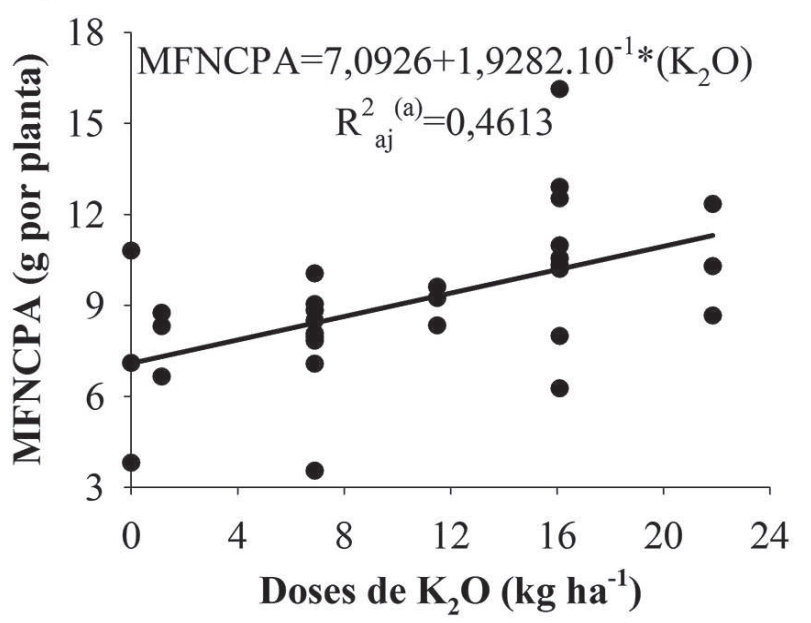

Figura 2: Matéria fresca não comercial da parte aérea (MFNCPA), em função de doses de $\mathrm{N}$ (A) e em função de doses de $\mathrm{K}_{2} \mathrm{O}$ (B). "Significativo pelo teste t de Student ( $\mathrm{p}<0,05)$; ${ }^{\text {(a) }}$ Coeficiente de determinação ajustado. 
dades da planta (Araújo et al, 2011). De fato, o excesso de nitrogênio leva a desequilíbrios nutricionais (Faquin, 1994). Neste experimento, a fertirrigação nitrogenada contribuiu com o crescimento da alface, sugerindo que a disponibilização diária de nitrogênio foi igual ou menor que a necessidade da planta.

Algumas das funções do potássio na planta relacionam-se com a ativação de enzimas associadas à fotossíntese e à respiração (Taiz \& Zeiger, 2004), à regulação do potencial osmótico e do turgor celular, à abertura e fechamento de estômatos (assimilação de gás carbônico) e ao transporte do produto da fotossíntese (Faquin \& Andrade, 2004).

Os efeitos benéficos da fertirrigação com doses de $\mathrm{K}_{2} \mathrm{O}$, para as respectivas características influenciadas, assim como para as quantidades de matérias frescas total e comercial da parte aérea, como já relatado previamente, também podem ser atribuídos, provavelmente, a um efeito do potássio maior do que do silício. Nestes casos, os favorecimentos dessas características podem ser atribuídos aos favorecimentos das diversas funções que o potássio exerce na planta, citadas anteriormente, além do que a adubação com este elemento pode ser vantajosa graças a um uso eficiente da água, assim como por favorecer a formação e translocação de carboidratos e melhorar a qualidade do produto (Filgueira, 2008).

Nas situações em que as características foram beneficiadas pela fertirrigação com nitrogênio, os favorecimentos podem ser explicados graças aos favorecimentos das funções que este elemento desempenha na planta, como na constituição de muitos componentes celulares, entre eles aminoácidos e ácidos nucleicos (Taiz \& Zeiger, 2004). Além disto, quando o nitrogênio é fornecido adequadamente, há benefícios para o crescimento vegetativo, assim como expansão da área fotossinteticamente ativa e elevação do potencial produtivo (Filgueira, 2008).

Ao considerar-se que, neste trabalho, não se efetuou adubação com molibdênio, é possível constatar que a dose em que foi obtida a maior resposta de matéria fresca comercial, por Resende et al. (2012), na ausência de molibdênio, foi numericamente menor que as relacionadas com os melhores resultados produtivos obtidos neste estudo. Entretanto, ambos os trabalhos verificaram influência positiva da adubação nitrogenada sobre o aspecto produtivo da cultura de alface.

Silva et al. (2008), na avaliação de alface americana, cultivar Raider, sobre a qual foram estudadas quatro lâminas de água, de 91,99, 142,79, 186,34 e 237,14mm, em combinação com quatro doses de nitrogênio, de 0, 80, 160 e $320 \mathrm{~kg} \mathrm{ha}^{-1}$, em casa de vegetação, concluíram que a produtividade física máxima estimada ocorreu com 208,03 mm e 290,5 $\mathrm{kg} \mathrm{ha}^{-1}$ de nitrogênio, o que concorda com os resultados deste estudo, no sentido de que em ambos os trabalhos constataram-se os benefícios da adubação nitrogenada sobre o aspecto produtivo da cultura da alface. Porém, a dose com a qual Silva et al. (2008) concluíram ter ocorrido a produtividade física máxima estimada foi numericamente maior que as que causaram os melhores resultados produtivos neste estudo.

Os resultados do estudo apresentado por Koetz et al. (2006) concordam com os deste trabalho, no qual se constatou influência positiva do fornecimento de potássio sobre aspectos produtivos da alface. Ainda que, neste trabalho, tenha sido observada interação negativa entre as doses de $\mathrm{N}$ e de $\mathrm{K}_{2} \mathrm{O}$, houve favorecimento de aspectos produtivos da alface com o fornecimento de nitrogênio e potássio, assim como observado para matéria fresca da parte comercial por Yuri (2004).
A.

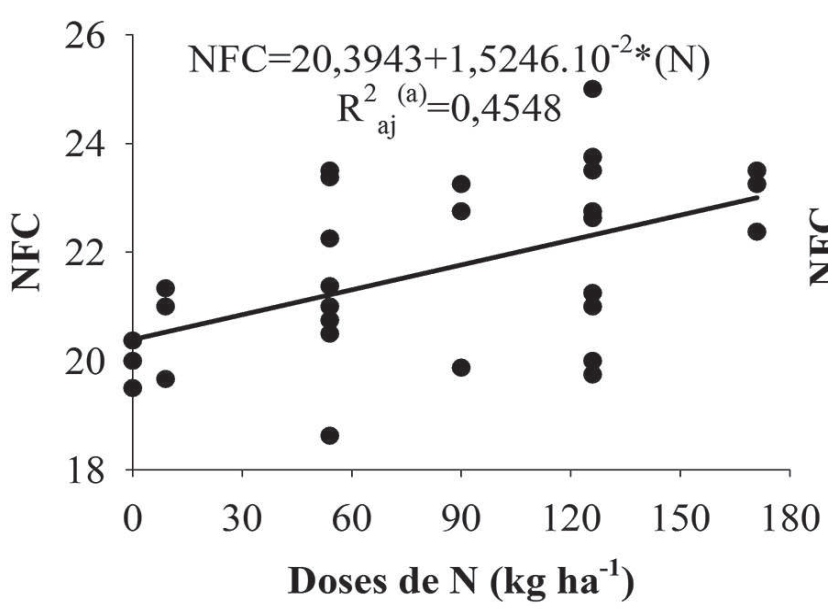

B.

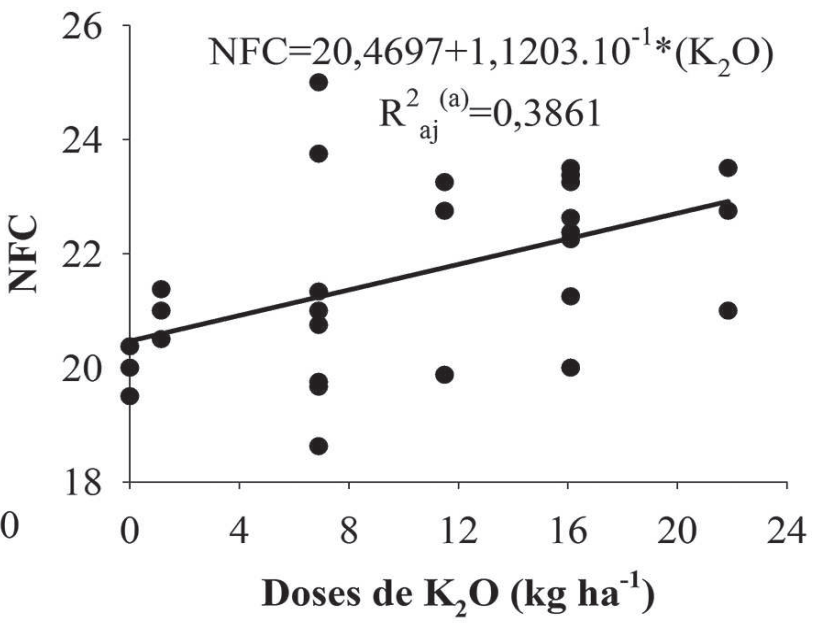

Figura 3: Número de folhas comerciais por planta (NFC), em função de doses de $\mathrm{N}$ (A) e em função de doses de $\mathrm{K}_{2} \mathrm{O}$ (B). "Significativo pelo teste $t$ de Student ( $\mathrm{p}<0,05)$; ${ }^{\text {(a) }}$ Coeficiente de determinação ajustado. 
Em experimento realizado para avaliação de oito cultivares de alface, Santos et al. (2011) não constataram diferença significativa entre os cultivares, com relação ao índice comercial e, mediante obtenção de uma média de 0,70 , relataram que, desta forma, apresentam boa qualidade comercial. $\mathrm{O}$ valor de índice comercial obtido neste trabalho, de 0,96 , foi numericamente maior que a média de 0,70 obtida por Santos et al. (2011). Assim, o valor de 0,96 apresentado neste estudo, com alface foi conduzida em ambiente protegido, possivelmente, caracteriza uma boa qualidade comercial de alface em razão do cultivo em ambiente protegido associado à irrigação por gotejamento, pois, nestas condições, pode haver, por exemplo, menor acúmulo de água sobre as folhas das plantas e, consequentemente, menor proliferação de doenças ou injúrias.

\section{CONCLUSÕES}

A fertirrigação de nitrogênio e potássio, aliada à adubação de plantio, pode ser utilizada para o aumento do crescimento da cultura da alface.

As maiores doses de nitrogênio e de potássio resultaram nas melhores repostas de número de folhas comerciais por planta.

O incremento da matéria fresca não comercial da parte aérea, obtido pela adubação com doses crescentes de nitrogênio e de potássio, não influenciou a qualidade comercial de alface.

\section{REFERÊNCIAS}

Araújo WF, Sousa KTS, Viana TVA, Azevedo BM, Barros MM \& Marcolino E (2011) Resposta da alface a adubação nitrogenada. Revista Agro@mbiente On-line, 5:12-17.

Beninni ERY, Takahashi HW \& Neves CSV (2005) Concentração e acúmulo de macronutrientes em alface cultivada em sistemas hidropônico e convencional. Semina: Ciências Agrárias, 26:273282

Carrijo OA, Marouelli WA \& Silva HR (1999) Manejo da água do solo na produção de hortaliças em cultivo protegido. Informe Agropecuário, 20:45-51.

Carvalho Filho JLS, Gomes LAA \& Maluf WR (2009) Tolerância ao florescimento precoce e características comerciais de progênies $\mathrm{F}_{4}$ de alface do cruzamento Regina 71 x Salinas 88. Acta Scientiarum. Agronomy, 31:37-42.

Duenhas LH, Villas Bôas RL, Souza CMP, Ragozo CRA \& Bull LT (2002) Fertirrigação com diferentes doses de NPK e seus efeitos sobre a produção e qualidade de frutos de laranja (Citrus sinensis O.) 'Valência'. Revista Brasileira de Fruticultura, 24:214-218.

Embrapa - Empresa Brasileira de Pesquisa Agropecuária (2013) Sistema brasileiro de classificação de solos. Brasília, Embrapa. $353 p$.

Faquin V (1994) Nutrição mineral de plantas. Lavras, ESALFAEPE. 227p.

Faquin V \& Andrade AT (2004) Nutrição mineral e diagnose do estado nutricional das hortaliças. Lavras, UFLA/FAEPE. 88p.
Fernandes HS \& Martins SR (1999) Cultivo de alface em solo em ambiente protegido. Informe Agropecuário, 20:56-63.

Filgueira FAR (2008) Novo manual de olericultura: agrotecnologia moderna na produção e comercialização de hortaliças. Viçosa, Editora UFV. 421p.

Frizzone JA, Freitas PSL, Rezende R \& Faria MA (2012) Microirrigação: gotejamento e microaspersão. Maringá, EDUEM. 356p.

Koetz M, Coelho G, Costa CC, Lima EP \& Souza RJ (2006) Efeito de doses de potássio e da freqüência de irrigação na produção da alface-americana em ambiente protegido. Engenharia Agrícola, 26:730-737.

Köppen W (1948) Climatología: con un estudio de los climas de la Tierra. México, Fondo de Cultura Económica. 172p.

Maggi MF, Klar AE, Jadoski CJ \& Andrade ARS (2006) Produção de variedades de alface sob diferentes potenciais de água no solo em ambiente protegido. Irriga, 11:415-427.

Mantovani JR, Ferreira ME \& Cruz MCP (2005) Produção de alface e acúmulo de nitrato em função da adubação nitrogenada. Horticultura Brasileira, 23:758-762.

Martins CM, Medeiros JF, Lopes WAR, Braga DF \& Amorim LB (2009) Curva de absorção de nutrientes em alface hidropônica. Caatinga, 22:123-128.

Resende GM, Alvarenga MAR, Yuri JE \& Souza RJ (2012) Rendimento e teores de macronutrientes em alface americana em função de doses de nitrogênio e molibdênio. Horticultura Brasileira, 30:373-378.

Santos D, Mendonça RMN, Silva SM, Espínola JEF \& Souza AP (2011) Produção comercial de cultivares de alface em Bananeiras. Horticultura Brasileira, 29:609-612.

Santos SR \& Pereira GM (2004) Comportamento da alface tipo americana sob diferentes tensões da água no solo, em ambiente protegido. Engenharia Agrícola, 24:569-577.

Silva PAM, Pereira GM, Reis RP, Lima LA \& Taveira JHS (2008) Função de resposta da alface americana aos níveis de água e adubação nitrogenada. Ciência e Agrotecnologia, 32:1266-1271.

Taiz L \& Zeiger E (2004) Fisiologia Vegetal. $3^{\mathrm{a}}$ ed. Porto Alegre, Artmed. 719p.

Turrent A \& Laird RJ (1975) La matriz experimental Plan Puebla, para ensayos sobre prácticas de producción de cultivos. Agrociencia, 19:117-143.

Vilas Boas RC, Carvalho JA, Gomes LAA, Souza KJ, Rodrigues RC \& Sousa AMG (2007) Efeito da irrigação no desenvolvimento da alface crespa, em ambiente protegido, em Lavras, MG. Revista Brasileira de Engenharia Agrícola e Ambiental, 11:393397.

Yuri JE (2004) Produção, nutrição e conservação pós-colheita da alface tipo americana, cv. Raider, no verão e no inverno, em função da aplicação de nitrogênio e potássio em cobertura. Tese de Doutorado. Universidade Federal de Lavras, Lavras. 139p. 